\title{
Aislamiento de una cepa de Enterococcus mundtii bacteriocinogénico proveniente de Hemiodema spectabilis (pepino de mar)
}

\author{
Isolation of bacteriocinogenic Enterococcus mundtii strain from Hemiodema \\ spectabilis (sea cucumber)
}

\author{
Marisol Vallejo ${ }^{1,2}$, Franco M. Sosa ${ }^{1}$, Romina B. Parada ${ }^{1}$, Luis F. Aguirre', \\ Emilio R. Marguet ${ }^{1}$
}

\section{Resumen}

En este estudio se evaluó la actividad antibacteriana de una cepa de Enterococcus mundtii tw278 productora de bacteriocina aislada del contenido intestinal de Hemiodema spectabilis (pepino de mar), recolectado en la costa patagónica de la Argentina. La cepa se identificó mediante pruebas bioquímicas y análisis filogenético del gen $\mathrm{ARNr} 16 \mathrm{~S}$. Además, se detectó el gen estructural que codifica para la mundticina KS mediante técnicas de PCR. La investigación de los factores de virulencia reveló que la cepa de $E$. mundtii tw278 no presentó actividad gelatinasa ni hemolítica y fue susceptible a todos los antibióticos analizados, excepto la cefalotina. La máxima actividad inhibitoria se logró al final de la fase logarítmica cuando se utilizó el caldo MRS como medio de cultivo a $35^{\circ} \mathrm{C}$. Luego de $12 \mathrm{~h}$ de incubación, el sobrenadante libre de células (SLC) alcanzó un título de 163840 unidades arbitrarias por mililitro contra la cepa indicadora de Listeria innocua ATCC 33090. El SLC exhibió actividad contra todas las cepas de Listeria ensayadas, Enterococcus faecalis ATCC 29212, enterococos resistentes a vancomicina (Van A, Van B y Van C), Lactobacillus plantarum TwLb 5 y Vibrio anguilarum V10. Este sería el primer estudio que informa el aislamiento de una cepa bacteriocinogénica de E. mundtii aislada del contenido intestinal de Hemiodema spectabilis.

Palabras clave: Enterococcus; mundticina; medio marino; Patagonia

${ }^{1}$ Laboratorio de Biotecnología Bacteriana, Facultad de Ciencias Naturales y Ciencias de la Salud, Sede Trelew, Universidad Nacional de la Patagonia San Juan Bosco (UNPSJB), Argentina

${ }^{2}$ E-mail: soltrelew@gmail.com

Trabajo financiado con fondos otorgados por la Agencia Nacional de Promoción Científica y Tecnológica - Ministerio de Ciencia y Tecnología (PICT-2014-0575) y la UNPSJB - Proyecto "Potencial biotecnológico de enterococos aislados del medio marino patagónico»

Recibido: 4 de abril de 2018

Aceptado para publicación: 14 de septiembre de 2018 
This study was conducted to evaluate the antibacterial activity of a bacteriocinproducing Enterococcus mundtii tw278 strain isolated from the intestinal content of Hemiodema spectabilis (sea cucumber) sampled in the Patagonian coast of Argentine. The strain was identified by biochemical tests and $16 \mathrm{~S}$ rRNA gene phylogenetic analyses. The structural gene that codifies mundticin KS was detected by PCR. Investigation of virulence factors revealed that $E$. mundtii tw278 did not display gelatinase or hemolytic activity and was susceptible to all antibiotics assayed, except cefalotin. Maximum inhibitory activity was achieved at the end of logarithmic phase when MRS broth was used as culture media at $35^{\circ} \mathrm{C}$. After $12 \mathrm{~h}$ of incubation, cell-free supernatant (CFS) reached a titre of 163840 arbitrary units per mililitre against the target bacteria Listeria innocua ATCC 33090. CFS showed activity against all the Listeria strains assayed, Enterococcus faecalis ATCC 29212, vancomycin-resistant enterococci (Van A, Van B and Van C), Lactobacillus plantarum TwLb 5 and Vibrio anguilarum V10. This would be the first study to report the isolation of a bacteriocinogenic E. mundtii strain from intestinal content of Hemiodema spectabilis.

Key words: Enterococcus; mundticin; marine environment; Patagonian

\section{INTRODUCCIÓN}

Los enterococos pertenecen al grupo de bacterias ácido lácticas (BAL). Son microorganismos ubicuos, y constituyen una gran proporción de la microflora autóctona que se encuentra en el tracto gastrointestinal de humanos y de una variedad de animales de granja y silvestres, así como en alimentos como la carne, leche y quesos (Laukova y Czikková, 2001; Belgacem et al., 2010). Pueden prolongar la vida útil de alimentos fermentados como resultado de la producción de agentes antimicrobianos, sintetizar compuestos que influyen en el sabor y contribuir a la promoción de la salud como cultivos probióticos (Gaggía et al., 2010). Sin embargo, algunas especies están asociadas e identificadas como agentes etiológicos de enfermedades intrahospitalarias, causando una alta incidencia de endocarditis, infecciones de las vías urinarias y en recién nacidos ( $\mathrm{Vu}$ y Carvalho, 2011). A pesar de estos rasgos negativos, en los últimos años ha cobrado relevancia el género Enterococcus, debido a que se caracteriza por una alta producción de bacteriocinas, conocidas en forma general como enterocinas. Las bacteriocinas son péptidos antimicrobianos catiónicos, de síntesis ribosomal, usualmente efectivos contra microorganismos filogenéticamente relacionados y, además, contra bacterias Gram positivas patógenas y/o que deterioran alimentos (Balciunas et al., 2013).

La eficacia de las enterocinas contra cepas patógenas como Listeria sp, Staphylococcus sp y Clostridium sp, entre otras, está bien documentada en varios sistemas alimentarios (Lauková y Czikková, 2001; Vera Pingitore et al., 2012); sin embargo, se dispone de poca información sobre el papel de las bacteriocinas en el tracto gastrointestinal. Se supone que la producción de bacteriocina es un mecanismo de defensa bacteriano, que proporciona a la cepa productora una ventaja competitiva contra microorganismos no productores y sensibles a la bacteriocina en el mismo nicho (Chen y Hoover, 2003).

La mayor parte de los estudios sobre la producción, caracterización, purificación y aplicación de las enterocinas se han llevado 
a cabo en cepas aisladas de humanos, animales de cría y alimentos (Zendo et al., 2005; Belgacem et al., 2010; Özdemir et al., 2011). En los últimos años son numerosos los trabajos que reportan especies del género Enterococcus productores de enterocinas aislados de vísceras de peces, tanto de agua dulce como salada (Migaw et al., 2013; Araújo et al., 2015; Ghomrassi et al., 2016). En comparación con otras especies de enterococos, el papel de las bacteriocinas producidas por Enterococcus mundtii apenas se ha estudiado en sistemas alimentarios, habiéndose determinado su eficacia en brotes de soja (Bennik et al., 1999), queso fresco Minas (Vera Pingitore et al., 2012) y salmón ahumado envasado al vacío (Bigwood et al., 2012).

En este estudio se evalúa la presencia de genes estructurales de enterocinas, los factores de virulencia mediante pruebas fenotípicas y la influencia del medio de cultivo, la temperatura y la fase de crecimiento sobre la producción de bacteriocina de la cepa E. mundtii tw278. Esta BAL se aisló del contenido intestinal de pepino de mar (Hemiodema spectabilis) y se seleccionó sobre la base de su actividad anti-Listeria.

\section{Materiales y Métodos}

\section{Microorganismo}

La cepa de E. mundtii tw278 fue originalmente aislada a partir del contenido intestinal de Hemiodema spectabilis (pepino de mar) proveniente de la costa noreste de la provincia del Chubut (Playa Unión - Argentina). Para este estudio se obtuvo de la colección perteneciente al Laboratorio de Biotecnología Bacteriana (Facultad de Ciencias Naturales y Ciencias de la Salud, Universidad Nacional de la Patagonia, Argentina). Se reactivó con sucesivos cultivos en caldo y agar de Man, Rogosa y Sharp (MRS, Biokar, Francia) y se conservó en Tripticasa Soja (TS) (Britania, Argentina) suplementa- da con glicerol al $10 \%$ a $-30{ }^{\circ} \mathrm{C}$. La identificación fenotípica se realizó en un trabajo previo (Parada et al., 2017), utilizando pruebas bioquímicas y fermentación de azúcares.

\section{Determinación de Factores de Virulencia}

\section{Actividad de la gelatinasa}

Se realizó en agar TS suplementado con $0.8 \%(\mathrm{~m} / \mathrm{v})$ de gelatina. La placa se incubó durante $48 \mathrm{~h}$ a $37{ }^{\circ} \mathrm{C}$ y se reveló con una solución de ácido tricloroacético al $20 \%(\mathrm{v} / \mathrm{v})$. Las zonas claras alrededor de la cepa se consideraron como positivas.

\section{Actividad hemolitica}

La producción de hemolisinas se evaluó en agar cerebro-corazón (Biokar, Francia) suplementado con sangre desfibrinada de conejo al 5\%, luego de una incubación a $37{ }^{\circ} \mathrm{C}$ durante $48 \mathrm{~h}$. Los resultados se interpretaron como positivos cuando se observó un halo de hemólisis completo alrededor de la colonia ( $\beta$-hemólisis).

\section{Producción de exopolisacáridos}

La producción de exopolisacáridos (EPS) de la cepa se evaluó de manera cualitativa en agar cerebro-corazón adicionado con sacarosa $50 \mathrm{~g} / \mathrm{l}$ y $0.8 \mathrm{~g} / \mathrm{l}$ de rojo Congo. La placa se incubó a $37^{\circ} \mathrm{C}$ durante $24 \mathrm{~h}$ y el resultado se interpretó como positivo cuando se observaron colonias de color negro.

\section{Sensibilidad a antibióticos}

Las susceptibilidades antibióticas se evaluaron mediante la prueba de difusión en disco en agar Mueller-Hinton (Britania, Argentina) por el método de Kirby-Bauer (Bauer et al., 1966). Los discos de sensibilidad a los antibióticos (Laboratorios Britania, Argentina) fueron: ampicilina $(10 \mu \mathrm{g})$, amoxicilina/ clavulánico $(20 / 10 \mu \mathrm{g})$, cefalotina $(30 \mu \mathrm{g})$ eritromicina $(15 \mu \mathrm{g})$, rifampicina $(5 \mu \mathrm{g})$, trimetoprima/sulfametoxazol $(1.25 / 23.75 \mu \mathrm{g}) \mathrm{y}$ 
vancomicina $(30 \mu \mathrm{g})$. Las placas se incubaron a $37{ }^{\circ} \mathrm{C}$ durante $24 \mathrm{~h}$. Las cepas Enterococcus faecalis ATCC 29212 y Staphylococcus aureus ATCC 25923 se utilizaron como microorganismos de control de calidad. Luego de la incubación se midieron los diámetros de los halos de inhibición de crecimiento, y los antibiogramas se interpretaron como sensible (S), intermedio (I) o resistente (R), de acuerdo a las recomendaciones del CLSI (2011).

\section{Actividad Inhibitoria del Sobrenadante}

La actividad antibacteriana se determinó luego de cultivar la cepa en caldo MRS a $30^{\circ} \mathrm{C}$ durante $18-20 \mathrm{~h}$. Luego del periodo de incubación, el cultivo se centrifugó a $8000 \mathrm{~g}$ a $4{ }^{\circ} \mathrm{C}$ durante $5 \mathrm{~min}$. El sobrenadante libre de células (SLC) se ajustó a pH 6.5-7 con $\mathrm{NaOH} 0.5 \mathrm{M}$ (Anedra, Argentina) y se sometió a un calentamiento de $100^{\circ} \mathrm{C}$ durante 5 min. Posteriormente, el SLC se filtró utilizando membranas Sartorius de $0.22 \mu \mathrm{m}$ de diámetro de poro (Sartorius, Alemania) y se almacenó a $-30{ }^{\circ} \mathrm{C}$ hasta la realización de los ensayos. La determinación de la actividad del SLC contra Listeria innocua ATCC 33090 se realizó por el método de difusión en placa, según lo descrito por Vallejo et al. (2014). En la evaluación del espectro de inhibición de la cepa E. mundtii tw278, seleccionada sobre la base de su actividad anti-Listeria, se utilizaron los microorganismos indicadores en las condiciones de crecimiento mencionadas en el Cuadro 1.

\section{Identificación Molecular}

La cepa de E. mundtii tw278 se incubó en caldo MRS a $35^{\circ} \mathrm{C}$ durante $18 \mathrm{~h}$. Posteriormente, el cultivo se centrifugó a $12000 \mathrm{~g}$ a $4{ }^{\circ} \mathrm{C}$ durante 5 min y el ADN genómico se extrajo utilizando el kit comercial de purificación Wizard Genomics (Promega, EEUU), siguiendo las instrucciones del fabricante. Mediante la reacción de PCR se amplificó el gen que codifica ARNr 16S utilizando un termociclador Multigene Gradient (Labnet International Inc., EEUU), usando los cebadores universales para procariotas $27 \mathrm{f}$ (5'-AGAGTTTGATCCTGGCTCAG- 3') y 1492r (5'-GGTTACCTTGTTACGACTT-3'), según lo describe DeLong (1992). Ambas hebras de los productos de PCR se secuenciaron utilizando los servicios comerciales de Macrogen Inc (Seúl, Corea). Las secuencias obtenidas se compararon con las depositadas en la base de datos del NCBI utilizando el programa BLAST (Basic Local Alignment Search Tool) (Altschul et al., 1990). La secuencia del gen ARNr 16S de la cepa seleccionada designada como $E$. mundtii tw278 (1271 pb) se depositó en la base de datos del GenBank bajo el número de acceso KY689401.

\section{Detección de Genes Estructurales de Enterocinas}

Los cebadores y protocolos utilizados en la reacción de PCR para la amplificación de los genes estructurales de las enterocinas se presentan en el Cuadro 2. Los productos de amplificación se analizaron mediante electroforesis en geles de agarosa (1.5\%) a $70 \mathrm{v}$ durante $1 \mathrm{~h}$ en buffer TAE (tris-acetatoEDTA) y se revelaron en bromuro de etidio $(1 \mu \mathrm{g} / \mathrm{ml})$.

\section{Influencia del Medio de Cultivo y Tem- peratura en la Producción de Enterocinas}

Con el propósito de evaluar la actividad inhibitoria en diferentes medios comerciales se utilizaron los caldos MRS, M17 (Biokar, Francia), cerebro-corazón (Biokar, Francia) y TS. Todos los caldos se incubaron a 10, 15 , $25,30,35,40$ y $45^{\circ} \mathrm{C}$ durante $24-48$ h y la actividad antimicrobiana se evaluó según lo descrito anteriormente utilizando L. innocua ATCC 33090.

\section{Curva de Crecimiento vs Actividad Anti- Listeria}

Se determinó la curva de crecimiento y la actividad de la bacteriocina producida en las condiciones óptimas determinadas en los ensayos anteriormente descritos, durante $24 \mathrm{~h}$. 
Cuadro 1. Actividad antimicrobiana de la cepa E. mundtii tw278

\begin{tabular}{|c|c|c|}
\hline Cepas indicadoras & $\begin{array}{l}\text { Medio de cultivo } \\
\text { y temperatura }\end{array}$ & $\begin{array}{c}\text { Actividad } \\
\text { antimicrobiana } \\
\text { E. } \text { mundtii tw } 278\end{array}$ \\
\hline Listeria innocua tw 67 & $\mathrm{TS}, 30^{\circ} \mathrm{C}$ & +++ \\
\hline L. innocua АТСС 33090 & $\mathrm{TS}, 30^{\circ} \mathrm{C}$ & ++ \\
\hline L. monocytogenes ATCC 7644 & $\mathrm{TS}, 35^{\circ} \mathrm{C}$ & +++ \\
\hline L. monocytogenes $1908^{\mathrm{a}}$ & $\mathrm{TS}, 35^{\circ} \mathrm{C}$ & +++ \\
\hline L. monocytogenes $1915^{\mathrm{a}}$ & $\mathrm{TS}, 35^{\circ} \mathrm{C}$ & +++ \\
\hline L. monocytogenes $1599^{\mathrm{a}}$ & $\mathrm{TS}, 35^{\circ} \mathrm{C}$ & +++ \\
\hline Enterococcus faecalis ATCC 29212 & MRS, $37^{\circ} \mathrm{C}$ & ++ \\
\hline Enterococcus Van A & MRS, $37^{\circ} \mathrm{C}$ & ++ \\
\hline Enterococcus Van B & MRS, $37^{\circ} \mathrm{C}$ & ++ \\
\hline Enterococcus Van C & MRS, $37^{\circ} \mathrm{C}$ & ++ \\
\hline E. casseliflavus & MRS, $37^{\circ} \mathrm{C}$ & +++ \\
\hline Lactococcus lactis ATCC 11454 & MRS, $30^{\circ} \mathrm{C}$ & - \\
\hline Lc. garvieae $03 / 8460^{\mathrm{b}}$ & MRS, $30^{\circ} \mathrm{C}$ & - \\
\hline Lc. garvieae $03 / 8702^{\mathrm{b}}$ & MRS, $30^{\circ} \mathrm{C}$ & - \\
\hline Lc. piscium $23.3 .92^{\mathrm{b}}$ & MRS, $30^{\circ} \mathrm{C}$ & - \\
\hline Streptococcus iniae MT $2376^{\mathrm{b}}$ & MRS, $37^{\circ} \mathrm{C}$ & - \\
\hline Lactobacillus plantarum TwLb 5 & MRS, $30^{\circ} \mathrm{C}$ & ++ \\
\hline Staphylococcus aureus ATCC 25923 & $\mathrm{TS}, 35^{\circ} \mathrm{C}$ & - \\
\hline Micrococcus luteus ATCC 15307 & $\mathrm{TS}, 30^{\circ} \mathrm{C}$ & - \\
\hline Escherichia coli ATCC 25922 & $\mathrm{TS}, 35^{\circ} \mathrm{C}$ & - \\
\hline E. coli ATCC 35218 & $\mathrm{TS}, 35^{\circ} \mathrm{C}$ & - \\
\hline Pseudomona aeruginosa ATCC 27853 & $\mathrm{TS}, 30^{\circ} \mathrm{C}$ & - \\
\hline Yersinia ruckerii 02/1607/C $\mathrm{C}^{\mathrm{b}}$ & $\mathrm{TS}, 25^{\circ} \mathrm{C}$ & - \\
\hline Vibrio anguilarum $\mathrm{V} 10^{\mathrm{b}}$ & $\mathrm{TS}, 25^{\circ} \mathrm{C}$ & ++ \\
\hline
\end{tabular}

Se tomaron muestras en forma aséptica cada $2 \mathrm{~h}$ para determinar su actividad antimicrobiana y densidad óptica (DO) a 600 $\mathrm{nm}$ en un espectrofotómetro Jenway 6400 . La actividad se definió como la recíproca de la dilución más alta que exhibió inhibición completa contra L. innocua ATCC 33090 y se expresó en unidades arbitrarias (AU) por mililitro de SLC.

\section{Resultados}

Los factores de virulencia evaluados mediante pruebas bioquímicas demostraron que la cepa de E. mundtii tw2 278 no presenta actividad de gelatinasa ni hemolítica; sin embargo, se detectó de manera cualitativa la producción de exopolisacáridos (EPS). La cepa presentó resistencia a cefalotina $(30 \mu \mathrm{g})$, 
Cuadro 2. Cebadores específicos para la detección de los genes estructurales de enterocinas mediante PCR

\begin{tabular}{|c|c|c|c|}
\hline Enterocinas & Secuencia $\left(5^{\prime}-3^{\prime}\right)$ & $\begin{array}{l}\text { Fragmento } \\
(\mathrm{pb})\end{array}$ & Referencia \\
\hline A & $\begin{array}{l}\text { entA f: GGTACCACTCATAGTGGAAA } \\
\text { entA r: CCCTGGAATTGCTCCACCTAA }\end{array}$ & 138 & $\begin{array}{l}\text { De Vuyst et } \\
\text { al., } 2003\end{array}$ \\
\hline B & $\begin{array}{l}\text { entB f: CAAAATGTAAAAGAATTAAGTACG } \\
\text { entB r: AGAGTATACATTTGCTAACCC }\end{array}$ & 201 & \\
\hline $\mathrm{P}$ & $\begin{array}{l}\text { entP f: GCTACGCGTTCATATGGTAAT } \\
\text { entP r: TCCTGCAATATTCTCTTTAGC }\end{array}$ & 87 & \\
\hline LB50A & $\begin{array}{l}\text { entL50A f: ATGGGAGCAATCGCAAAATTA } \\
\text { entL50A r: TTTGTTAATTGCCCATCCTTC }\end{array}$ & 274 & \\
\hline LB50B & $\begin{array}{l}\text { entL50B f: ATGGGAGCAATCGCAAAATTA } \\
\text { entL50B r: TAGCCATTTTTCAATTTGATC }\end{array}$ & 274 & \\
\hline 91 & $\begin{array}{l}\text { ent } 96 \text { f: GTGGAGAGGACGAAAGGAGA } \\
\text { ent } 96 \text { r: TTGATTAGTGGAGAGGACGGATTA }\end{array}$ & 291 & $\begin{array}{l}\text { Henning et } \\
\text { al., } 2015\end{array}$ \\
\hline 31 & $\begin{array}{l}\text { bact } 31 \mathrm{f:} \text { CCTACGTATTACGGAAATGGT } \\
\text { bact } 31 \mathrm{r}: \text { GCCATGTTGTACCCAACCATT }\end{array}$ & 130 & $\begin{array}{l}\text { Özdemir et } \\
\text { al., } 2011\end{array}$ \\
\hline $1071 \mathrm{~A} / \mathrm{B}$ & $\begin{array}{l}\text { Ent } 1071 \text { f: GGGGAGAGTCGGTTTTTAG } \\
\text { Ent } 1071 \text { r: ATCATATGCGGGTTGTAGCC }\end{array}$ & 273 & $\begin{array}{l}\text { Martín et al., } \\
2006\end{array}$ \\
\hline EntQ & $\begin{array}{l}\text { entQ f: ATGAATTTTCTTCTTAAAAATGGTATCGCA } \\
\text { ent Q r: TTAACAAGAAATTTTTTCCCATGGCAA }\end{array}$ & 105 & $\begin{array}{l}\text { Belgacem et } \\
\text { al., } 2010\end{array}$ \\
\hline KS & $\begin{array}{l}\text { mun KS f: TGAGAGAAGGTTTAAGTTTTGAAGAA } \\
\text { mun KS r: TCCACTGAAATCCATGAATGA }\end{array}$ & 379 & $\begin{array}{l}\text { Zendo et al., } \\
2005\end{array}$ \\
\hline
\end{tabular}

mientras que resultó sensible al resto de los antibióticos ensayados.

La identificación bioquímica se confirmó mediante el secuenciamiento del gen ARNr 16S y posterior comparación con las secuencias existentes en la base de datos del GenBank. La cepa estudiada exhibió un 100\% de homología con E. mundtii DSM 4838.

La actividad antimicrobiana se evaluó contra microorganismos Gram positivos y negativos, mediante el método de difusión en placa (Cuadro 1). Los resultados demuestran que la cepa presenta actividad contra el género Listeria y otras BAL, y dentro del grupo de bacterias Gram negativas ensayadas solo se detectó inhibición contra Vibrio anguilarum.
Mediante la técnica de PCR se evaluó la presencia de genes estructurales conocidos de enterocinas de la clase II: subclase II. 1 «familia de las pediocinas» (enterocina A, P, bact 31, mun KS), subclase II.2 «sin péptido señal» (enterocina Q, L50A y L50B) y subclase II.3 «estructura lineal» (enterocina B, 96 y 1071 A/B) empleando cebadores específicos. Solo se obtuvo una amplificación con el cebador para la mundticina KS (de tamaño compatible con lo esperado). Este resultado indica que la cepa presenta el gen mun $K S$ y expresa la mencionada enterocina (datos no mostrados).

El efecto de la temperatura sobre la producción de la enterocina se estudió en caldo MRS, M17, TS y BHI en un rango de 10 a $45{ }^{\circ} \mathrm{C}$ (datos no mostrados). La mayor acti- 

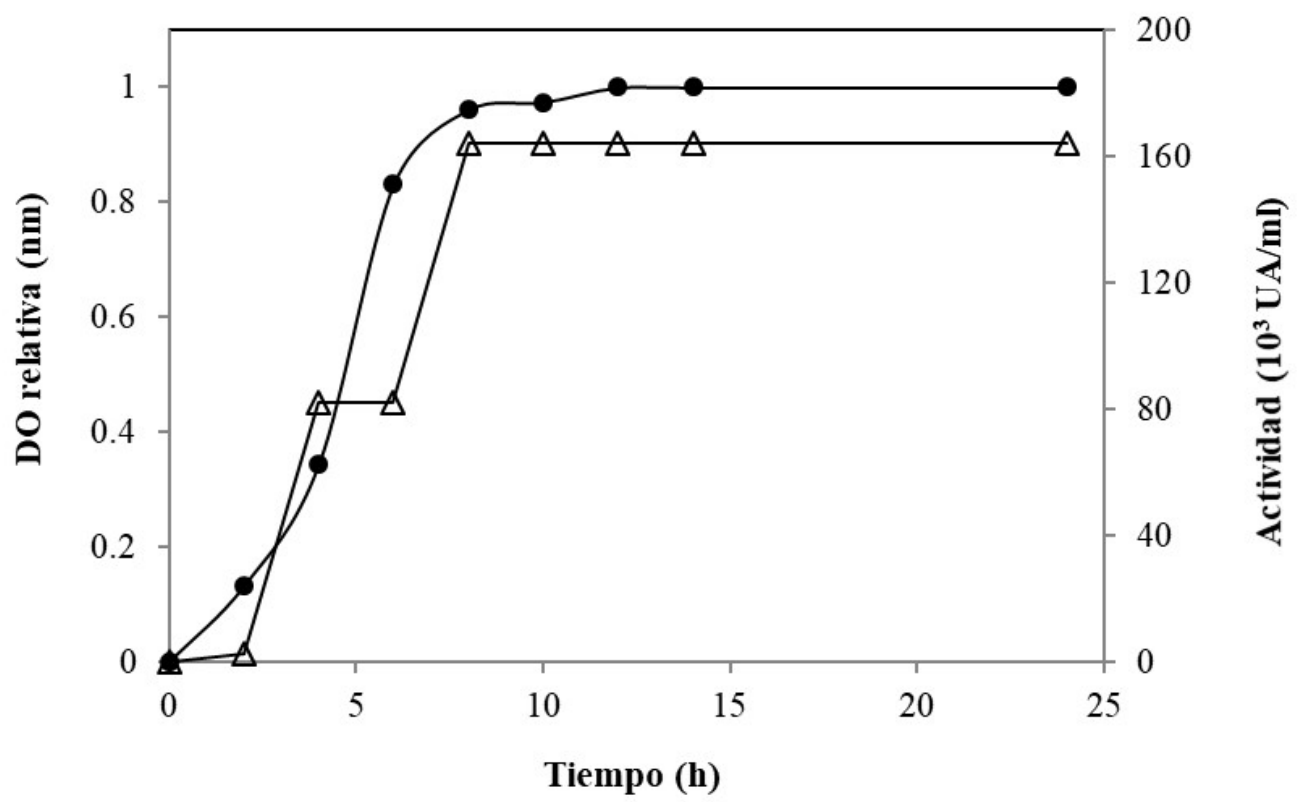

Figura 1. Curva de crecimiento $(\bullet)$ expresada en DO relativa y actividad antimicrobiana $(\Delta)$ de E. mundtii Tw278 en función de tiempo

vidad anti-Listeria se observó en los SLC provenientes de caldo MRS en el rango de temperatura $10-40^{\circ} \mathrm{C}$, obteniéndose un máximo a $35^{\circ} \mathrm{C}$; mientras que a $45^{\circ} \mathrm{C}$ se produjo un descenso de la actividad inhibitoria. Resultados similares se obtuvieron con el caldo BHI, aunque siempre la actividad resultó inferior si se la compara con el medio MRS. Por otra parte, los medios M17 y TS resultaron poco adecuados para la producción de enterocina por parte de la cepa E. mundtii tw278.

La Figura 1 muestra la curva de crecimiento, expresada en DO relativa y el perfil de producción de enterocina en caldo MRS a $35^{\circ} \mathrm{C}$ durante $24 \mathrm{~h}$ (condiciones óptimas). La producción comienza a partir de las $2 \mathrm{~h}$ de incubación, obteniéndose la máxima actividad (163 $840 \mathrm{UA} / \mathrm{ml})$ en el final de la fase exponencial y permaneciendo constante durante toda la fase estacionaria.

\section{Discusión}

Los enterococos constituyen una fracción importante de la microbiota intestinal autóctona de los mamíferos y otros animales. Una vez liberados al ambiente junto con las excretas, son capaces de colonizar diversos nichos ecológicos gracias a su capacidad para sobrevivir a las condiciones ambientales desfavorables y crecer en ambientes hostiles (Byappanahalli et al., 2012). Estudios previos sugerían que este género microbiano no estaba usualmente asociado con ambientes acuáticos; sin embargo, su presencia es común en animales, tanto vertebrados como invertebrados marinos (Gómez-Sala et al., 2015).

Las BAL se consideran microorganismos totalmente inocuos para su incorporación en los alimentos. No obstante, el 
estatus de GRAS (microorganismos reconocidos como seguros, por sus siglas en inglés) no se extiende al género Enterococcus, debido a su carácter de patógeno oportunista ocasionando una cantidad considerable de infecciones nosocomiales adquiridas (Henning et al., 2015). La expresión de la gelatinasa (enzima capaz de degradar a la gelatina, caseína y otros péptidos bioactivos) como la actividad hemolítica, constituyen algunos de los factores de virulencia importantes desde el punto de vista clínico a evaluar en el género Enterococcus. Se ha demostrado experimentalmente que la citolisina es una proteína que aumenta la patogenicidad en enfermedades enterocócicas en los modelos animales ensayados (Semedo et al., 2003). La presencia y expresión de factores de virulencia parece estar íntimamente relacionada con el origen de las cepas (Eaton y Gasson, 2001). La cepa E. mundtii tw278 evaluada en este estudio no presentó actividad gelatinasa ni hemolítica en placa.

La producción de EPS desempeña un factor de interés industrial o un rasgo negativo a evaluar junto con otros factores de virulencia, según el origen y género de las BAL productoras. La producción de EPS juega un papel clave para la elaboración de quesos y yogures. Por otro lado, es importante determinar si la cepa productora exhibe rasgos de patogenicidad, ya que los EPS están relacionados con la capacidad de formar biofilm y la posibilidad de colonizar superficies inertes utilizadas habitualmente en clínica (Eaton y Gasson 2001). Según el resultado obtenido, sería prematuro clasificar a la cepa de $E$. mundtii tw278 como patógena por solo este rasgo. Se debe estudiar otros factores de patogenicidad relacionados con la producción de EPS, como la sustancia de agregación, cuya presencia incrementa considerablemente la adherencia a los túbulos renales, a células intestinales e internalización enterocóccica en los macrófagos (Eaton y Gasson 2001).

Los enterococos se caracterizan por presentar resistencia intrínseca de grado variable a un gran número de antibióticos, pue- den adquirir nuevas resistencias con una gran facilidad y contribuir a la diseminación fuera del ámbito hospitalario (Vu y Carvalho, 2011). En este estudio, la susceptibilidad de la cepa a los antibióticos evaluados, particularmente vancomicina y ampicilina, resultan de interés debido a que la resistencia a estos agentes determina la pérdida de sinergia entre aminoglucósidos y agentes activos sobre la pared celular, fundamental para el tratamiento de infecciones invasivas causadas por enterococos. La resistencia a cefalotina no presenta relevancia desde el punto de vista clínico, debido a que el género Enterococcus exhibe una resistencia natural a este antimicrobiano.

Las bacteriocinas producidas por bacterias Gram positivas están clasificadas en cuatro clases dependiendo de su tamaño, estructura, propiedades químicas y físicas (Balciunas et al., 2013). En este estudio, solo se detectó una amplificación de 380 pb cuando se utilizaron los cebadores específicos para la detección del gen estructural de la mundticina KS (Zendo et al., 2005). La mencionada enterocina pertenece a la clase II (subclase II.1), familia de las pediocinas, con actividad anti-Listeria, alta estabilidad térmica y sensible a tripsina, según Parada et al. (2017). Si bien se dispone de estudios sobre enterococos bacteriocinogénicos provenientes de alimentos (Belgacem et al., 2010), son escasos los estudios en cepas de origen marino (Migaw et al, 2013; Gómez-Sala et al., 2015; Ghomrassi et al., 2016), y en el caso particular de E. mundtii, los reportes indican que las cepas provienen de nichos diferentes al marino (Zendo et al., 2005; Bigwood et al., 2012; Vera Pingitore et al., 2012). Cabe destacar, que la enterocina producida por esta cepa no solo fue activa contra cepas de bacterias Gram positivas, sino también contra $V$. anguilaum, característica inusual para bacteriocinas de BAL. El medio marino, específicamente el patagónico, ha demostrado un gran potencial como fuente de BAL productoras de bacteriocinas (Sequeiros et al, 2010; Schelegueda et al., 2015), con potencial aplicación en acuicultura y preservación de alimentos provenientes de la pesca. 
Los resultados obtenidos de producción de enterocina en diferentes medios y temperaturas de incubación son similares a trabajos previos en los que se utilizan medios comerciales y/o modificados (Settanni et al., 2008; Todorov y Dicks, 2009). En el presente estudio, la máxima actividad anti-Listeria se obtuvo cuando se empleó el caldo MRS. El cultivo en caldo BHI exhibió resultados comparables con el caldo MRS, mientras que el M17 y TS resultaron poco eficientes para la producción de bacteriocina. Todos estos medios no selectivos son recomendados para el crecimiento de enterococos; sin embargo, la síntesis de la bacteriocina se vio marcadamente disminuida cuando se utilizaron el M17 y TS.

La síntesis de bacteriocinas depende principalmente de la fuente de nitrógeno utilizada y de carbono (carbohidratos). Este efecto se demostró modificando la composición del caldo MRS en el estudio de Vallejo et al. (2014) con la cepa de E. mundtii Tw56 aislado del contenido intestinal de pejerrey (Odontesthes platensis). Tanto el MRS como el BHI son medios que incluyen en sus formulaciones polipeptonas, hidrolizados y extractos de carne, fuentes de nitrógeno que estimulan la biosíntesis de péptidos antimicrobianos, mientras que el TS y M17 difieren de los anteriores en su cantidad y composición proteica. La selección de una adecuada fuente de carbono es importante para lograr una rápida duplicación celular y alcanzar una población suficiente que pueda sintetizar altos niveles de bacteriocinas (Settanni et al., 2008; Todorov y Dicks, 2009; Vallejo et al. 2014). Trabajos previos sobre la optimización de los medios para la producción de bacteriocinas resultan contradictorios, toda vez que Aasen et al. (2000) y Todorov y Dicks (2004) demostraron que la producción de bacteriocinas puede lograrse en condiciones subóptimas, pero Settanni et al. (2008) determinaron que condiciones de estrés y deficientes concentraciones de factores nutricionales reducen drásticamente la producción de bacteriocinas en cepas de $E$. mundtii.
En general, la producción de bacteriocinas por BAL es un proceso sensible a la temperatura, por lo que no necesariamente su síntesis coincide con la temperatura óptima de crecimiento de la cepa (Leroy y De Vuyst, 1999). Delgado et al. (2005) sugirieron que la producción de bacteriocina se mejora cuando los microorganismos son cultivados en condiciones subóptimas de temperatura. No obstante, en el presente estudio la máxima producción se obtuvo a $35^{\circ} \mathrm{C}$, coincidiendo con Settanni et al. (2008) y Vallejo et al. (2014). A diferencia de otros enterococos proveniente de peces (Migaw et al., 2013), la cepa E. mundtii tw 278 no solo logró crecimiento poblacional cuando se la incubó a $10^{\circ} \mathrm{C}$ durante $48 \mathrm{~h}$, sino que además sintetizó bacteriocina. En consecuencia, la temperatura de incubación, la composición y modificación de los medios de cultivos podrían influenciar de manera positiva en la cantidad y actividad de la enterocina sintetizada. Estos parámetros, entre otros, deberían ser considerados a futuro con el propósito de optimizar la producción por parte de la cepa E. mundtii tw278.

La Figura 1 muestra una fase lag breve, seguida por una fase logarítmica que alcanzó el máximo poblacional a las $12 \mathrm{~h}$ de incubación. La actividad de la bacteriocina se detectó a partir de las $2 \mathrm{~h}$ de incubación (2560 UA/ml) y llegó a su máximo a las $12 \mathrm{~h}$ donde alcanzó las $163840 \mathrm{UA} / \mathrm{ml}$. A diferencia de otros trabajos (Todorov y Dicks, 2009; Vallejo et al., 2014), la actividad permaneció constante durante toda la fase estacionaria. En este estudio, como en otros (Migaw et al., 2014; Ghomrassi et al., 2016), se demostró que la producción de la bacteriocina mantiene relación con el aumento de la biomasa; aunque este fenómeno no siempre está correlacionado con la concentración celular o la tasa de crecimiento (Delgado et al., 2005). Los resultados de actividad anti-Listeria, expresados en UA/ml, y el espectro de inhibición resultan de gran interés y son comparables a los obtenidos por otros autores (Settanni et al., 2008; Ghomrassi et al., 2016). 
Conclusiones

La costa marina patagónica ofrece un hábitat con características fisicoquímicas y biológicas propias que permite el aislamiento de microorganismos con propiedades fisiológicas diferentes a las que se aíslan tradicionalmente de alimentos o de otros hábitats más explorados. Este sería el primer estudio que informa el aislamiento de una cepa bacteriocinogénica de E. mundtii aislada del contenido intestinal de Hemiodema spectabilis. Los altos valores de actividad anti-Listeria y la producción a bajas temperaturas hacen factible el potencial uso de la cepa como bio-preservante en alimentos.

\section{Literatura Citada}

\section{Aasen IM, Moretro T, Katla T,} Axelsson L, Storro I. 2000. Influence of complex nutrients, temperature and $\mathrm{pH}$ on bacteriocin production by Lactobacillus sakei CCUG 42687. Appl Microbiol Biot 53: 159-166. doi: 10.1007/ s002530050003

2. Altschul SF, Gish W, Miller M, Myers EW, Lipman DJ. 1990. No basic local alignment search tool. J Mol Biol 215: 403-410. doi: 10.1016/S00222836(05)80360-2

3. Araújo C, Muñoz-Atienza E, Hernández PE, Herranz C, Cintas LM, Igrejas G, Poeta P. 2015. Evaluation of Enterococcus spp from rainbow trout (Oncorhynchus mykiss, Walbaum), feed, and rearing environment against fish pathogens. Foodborne Pathog Dis 12: 311-322. doi: 10.1089/fpd.2014.1906.

4. Balciunas EM, Castillo FA, Todorov $S D$, Gombossy BD, Converti $A$, Oliveira PR .2013. Novel biotech- nological applications of bacteriocins: a review. Food Control 32: 134-142. doi: 10.1016/j.foodcont.-2012.11.025.

5. Bauer AW, Kirby WMM, Sherris JC, TURK M. 1966. Antibiotic susceptibility testing by a standardized single disk method. Am J Clin Pathol 45: 493-496. doi: 10.1093/ajcp/45.4_ts.493

6. Belgacem ZB, Abriouel H, Omar NB, Lucas $R$, Martínez-Canamero $M$, Gálvez A, Manai M. 2010. Antimicrobial activity, safety aspects, and some technological properties of bacteriocinogenic Enterococcus faecium from artisanal Tunisian fermented meat. Food Control 21: 462-470. doi: 10.1016/ j.foodcont.2009.07.007

7. Bennik MH, van Overbeek W, Smid EJ, Gorris LG 1999. Biopreservation in modified atmosphere stored mung bean sprouts: the use of vegetable associated bacteriocinogenic lactic acid bacteria to control the growth of Listeria monocytogenes. Lett Appl Microbiol 28: 226-232. doi: 10.1046/j.1365-2672.1999.00497.x

8. Bigwood T, Hudson JA, Cooney J, McIntyre L, Billington C, Heinemann $J A$, Wall F. 2012. Inhibition of Listeria monocytogenes by Enterococcus mundtii isolated from soil. Food Microbiol 32: 354-360. doi: 10.1016/ j.fm.2012.07.015

9. Byappanahalli MN, Nevers $M$, Korajkic A, Staley ZR, Harwood VJ. 2012. Enterococci in the environment. Microbiol Mol Biol R 76: 685-706. doi: 10.1128/MMBR.00023-12

10. Chen H, Hoover DG, 2003. Bacteriocins and their food applications. Compr Rev Food Sci F 2: 82-100. doi: 10.1111/j.1541-4337.2003.tb00016.x

11. [CLSI] Clinical and Laboratory Standards Institute. 2011. Performance standards for antimicrobial susceptibility testing: twenty-first informational supplement M100-S21. Wayne, USA: CLSI. 168 p. 
12. de Vuyst L, Foulquié-Moreno M, Reverts $H$. 2003. Screening for enterocins and detection of hemolysin and vancomycin resistance in enterococci of different origins. Int J Food Microbiol 84: 299-318. doi: 10.1016/S01681605(02)00425-7

13. Delgado A, Brito D, Peres C, Noé-Arroyo F, Garrido-Fernández, A. 2005. Bacteriocin production by Lactobacillus pentosus B96 can be expressed as a function of temperature and $\mathrm{NaCl}$ concentration. Food Microbiol 22: 521-552. doi: 10.1016/j.fm.2004.-11.015

14. DeLong EF. 1992. Archaea in coastal marine environments. P Natl Acad Sci USA 89: 5685-5689.

15. Eaton TJ, Gasson MJ. 2001. Molecular screening of Enterococcus virulence determinants and potential for genetic exchange between food and medical isolates. Appl Environ Microb 67: 1628-1635. doi: 10.1128/ AEM.67.4.1628-1635.2001

16. Gaggía F, Mattarelli P, Biavati B. 2010. Probiotics and prebiotics in animal feeding for safe food production. Int J Food Microbiol 141: 15-28. doi: 10.1016/ j.ijfoodmicro.2010.02.031

17. Ghomrassi H, ben Braiek O, Choiset Y, Haertlé T, Hani K, Chobert JM, Ghrairi T. 2016. Evaluation of marine bacteriocinogenic enterococci strains with inhibitory activity against fishpathogenic Gram-negative bacteria. Dis Aquat Organ 118: 31-43. doi: 10.3354/ dao02953.

18. Gómez-Sala B, Muñoz-Atienza E, Sánchez J, Basanta A, Herranz C, Hernández PE, Cintas LM. 2015. Bacteriocin production by lactic acid bacteria isolated from fish, seafood and fish products. Eur Food Res Technol 241: 341-356. doi: 10.1007/s00217-015-2465-3.

19. Henning C, Gautam D, Muriana P. 2015. Identification of multiple bacteriocins in Enterococcus spp using an Enterococcus-specific bacteriocin PCR array. Microorganisms 3: 1-16. doi: 10.3390/microorganisms3010001
20. Lauková A, Czikková S. 2001. Antagonistic effect of enterocin CCM 4231 from Enterococcus faecium on "bryndza», a traditional Slovak dairy product from sheep milk. Microbiol Res 156: 31-34. doi: 10.1078/0944-501300078

21. Leroy F, de Vuyst L. 1999. Temperature and $\mathrm{pH}$ conditions that prevail during fermentation of sausages are optimal for production of the antilisterial bacteriocina sakacin K. Appl Environ Microb 65: 974-981.

22. Martín M, Gutiérrez J, Criado R, Herranz C, Cintas LM, Hernández $P E$. 2006. Genes encoding bacteriocins and their expression and potential virulence factors of enterococci isolated from wood pigeons (Columba palumbus). J Food Protect 69: 520-531. doi: 10.4315/0362-028X-69.3.520

23. Migaw S, Ghrairi T, Le Chevalier P2, Brillet B, Fleury Y, Hani K. 2013. Isolation and characterization of enterococci bacteriocinic strains from Tunisian fish viscera. Food Nut Sci 4:701708. doi: 10.4236/fns. 2013.46089

24. Migaw S, Ghrairi T, Belguesmia Y, Choiset Y, Berjeaud JM, Chobert JM, Hani K, Haertlé T. 2014. Diversity of bacteriocinogenic lactic acid bacteria isolated from Mediterranean fish viscera. World J Microbiol Biotechnol 30: 12071217. doi: 10.1007/s11274-013-1535-6

25. Özdemir GB, Oryapýn E, Býyýk HH, Özteber M, Bozdoçan B. 2011. Phenotypic and genotypic characterization of bacteriocins in enterococcal isolates of different sources. Indian $\mathbf{J}$ Microbiol 51: 182-187.

26. Parada R, Beraud L, Andoro D, Sosa F, Marguet ER, Vallejo M. 2017. Actividad antimicrobiana de bacterias ácido lácticas aisladas de invertebrados marinos de la costa del Chubut (Patagonia, Argentina). Bionatura 2:456-459. doi: 10.21931/RB/2017.02.04.8

27. Schelegueda LI, Vallejo M, Gliemmo MA, Marguet ER, Campos CA. 2015. Synergistic antimicrobial action and 
potential application for fish preservation of a bacteriocin produced by Enterococcus mundtii isolated from Odontesthes platensis. Food Sci Biotechnol 64: 794-801. doi: 10.1016/ j.lwt.2015.06.017

28. Semedo T, Almeida M, Martins P, Silva MF, Figueiredeo JJ, Tenreiro R, Barreto MT. 2003. Comparative study using type strains and clinical and food isolated to examine hemolytic activity and occurrence of the cyl operon in enterococci. J Clin Microbiol 41: 2569-2576. doi: 10.1128/JCM.41.6.2569-2576.2003

29. Sequeiros C, Vallejo M, Marguet ER, Olivera NL. 2010. Inhibitory activity against the fish pathogen Lactococcus garvieae produced by Lactococcus lactis TW34, a lactic acid bacterium isolated from the intestinal tract of a Patagonian fish. Arch Microbiol 192: 237245. doi: 10.1007/s00203-010-0552-1

30. Settanni L, Valmorri S, Suzzi G, Corsetti A. 2008. The role of environmental factors and medium composition on bacteriocin like inhibitory substances (BLIS) production by Enterococcus mundtii strains. Food Microbiol 25: 722-728. doi: 10.1016/ j.fm.2008.01.011

31. Todorov SD, Dicks LM. 2004. Effect of medium components on bacteriocin production by Lactobacillus pentosus ST151BR, a strain isolated from beer produced by the fermentation of maize, barley and soy flour. World J Microb Biot 20: 643-650.
32. Todorov SD, Dicks LM. 2009. Effect of modified MRS medium on production and purification of antimicrobial peptide ST4SA produced by Enterococcus mundtii. Anaerobe 15: 65-73. doi: 10.1016/j.anaerobe.2008.11.002

33. Vallejo M, Ledesma P, Anselmino L, Marguet ER. 2014. Efecto de las condiciones de crecimiento y composición del medio de cultivo sobre la producción de bacteriocina de Enterococus mundtii Tw56. Rev Colomb Biotecnol 16: 174179. doi: 10.15446/rev.colomb.biote.v16n2.47238

34. Vera Pingitore E, Todorov SD, Sesma F, Franco BD. 2012. Application of bacteriocinogenic Enterococcus mundtii CRL35 and Enterococcus faecium $\mathrm{ST} 88 \mathrm{Ch}$ in the control of Listeria monocytogenes in fresh Minas cheese. Food Microbiol 32: 38-47. doi: 10.1016/ j.fm.2012.04.005

35. Vu J, Carvalho J. 2011. Enterococcus: review of its physiology, pathogenesis, diseases and the challenges it poses for clinical microbiology. Front Biol 65: 357366. doi: 10.1007/s11515-011-1167-x

36. Zendo T, Eungruttanagorn N, Fujioka $S$, Tashiro Y, Nomura K, Sera Y, Kobayashi G, et al. 2005. Identification and production of a bacteriocin from Enterococcus mundtii QU 2 isolated from soybean. JAppl Microbiol 99: 11811190. doi: 10.1111/j.1365-2672.2005.02704.x 